\title{
Aspectos legales en un cambio de cultura en la relación médico-paciente
}

\author{
José Alejandro Inostroza Mandriaza
}

Médico Cirujano, Universidad de Chile. Pediatra, Magíster en Pediatría, Pontificia Universidad Católica de Chile

Magíster en Derecho de la Salud de la Universidad de los Andes

Jefe de Servicio de Pediatría Integramédica

Desde un tiempo a esta parte, una serie de factores, no siempre relacionados entre sí, han generado una serie de problemas de índole legal, que tienen a muchos médicos e instituciones no tan sólo preocupados y ocupados, sino tratando de buscar iniciativas que le brinden mayor seguridad, tanto a sus pacientes, como a ellos.

Todo esto, en un contexto que ha generado un empoderamiento de los pacientes, no siempre bien entendido, lo que ha producido un sentimiento de inseguridad por parte de los profesionales de la salud $\mathrm{y}$ un aumento de posibilidades de litigiosidad, esto es, reclamos, demandas e incluso agresiones.

A esto, se suma la progresiva tipificación de derechos del paciente, cuyo cumplimiento puede ser exigido ante tribunales, como por ejemplo los derechos a ser tratado con dignidad, a la confidencialidad de sus datos sensibles, a adoptar decisiones informadas y a las garantías de las prestaciones de salud.

Esta dinámica, ha generado cambios en la práctica asistencial, con tendencias a producir una atención más estandarizada, acercándose un poco a lo que conocemos como medicina defensiva ${ }^{1}$.

Nuestra relación con los pacientes está migrando, de médica a sanitaria, de ser un paciente a ser un con-

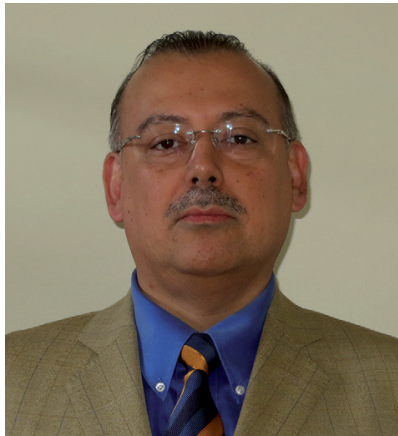

sumidor $^{2}$ (que incluso puede canalizar sus reclamos en SERNAC), tal cual se hace con una casa comercial, y las relaciones con el paciente, más que personales, son institucionales. Visto así, la despersonalización de la relación entre el médico y el paciente debilita la antigua relación de confianza con el médico de cabecera, que era el referente anterior.

Los avances en la medicina, muchas veces aumentan los riesgos de error y no siempre permiten distinguir con relativa precisión un diagnóstico o tratamiento, más aún, el tiempo va acotando su utilidad y la experiencia con ellos va determinando conductas diferentes a las iniciales. Esto adquiere una mayor dimensión por el interés particular que nuestra época presta a la vida y la salud y en particular la menor tolerancia a los riesgos de vida, aunque estos estén informados.

Por otra parte, hay un incentivo de los abogados a plantear acciones con baja probabilidad de éxito, que aunque tengan bajas probabilidades de ganar, son llevadas adelante, dado que la repercusión en la prensa, da cuenta de una mejor expectativa, más aún si no le significan una perdida al paciente, que lleva adelante su acción por un porcentaje de lo que se logre ${ }^{1}$.

Esta situación, no debemos abordarla sintiéndonos víctimas de un problema que cambia fuera de 
nuestro alcance, ya que esta visión nos paraliza y nos induce, por ejemplo, a ejercer una medicina defensiva ${ }^{1}$, despojada de los pensamientos y riesgos controlados, que nos hacen muchas veces, encontrar los reales problemas de salud de nuestros pacientes.

Por el contrario, lo mejor es que seamos protagonistas de integrar estas visiones, para que tanto nuestros pacientes, como los médicos, encontremos caminos que nos conduzcan con nitidez en la búsqueda de sanar a nuestros enfermos.

La calidad, desde el punto de vista argumental, se sostiene por la seguridad. Es ella, entonces, la que debe guiar la creación de una interfaz, que conecte a los médicos con este ámbito, lo que mejorará las expectativas y calidad de vida de nuestros pacientes y de nuestros colegas.

\section{Referencias}

1. Barros Bourie E. Tratado de responsabilidad extracontractual. Santiago, Editorial Jurídica 2006; 656-94 pp.

2. Jena AB, Schoemaker L, Bhattacharya J, Seabury SA.

Physician spending and subsequent risk of malpractice claims: observational study. BMJ 2015;351:h5516. 